\title{
Time-dependent failure criterion for cemented paste backfills
}

\author{
T. Belem Université du Québec en Abitibi-Témiscamingue, Canada
}

A.B. Fourie The University of Western Australia, Australia

M. Fahey The University of Western Australia, Australia

\begin{abstract}
In this paper, a simple time-dependent failure criterion has been proposed for cemented paste backfills. In addition to curing time, it allows to take into account the binder content that will be responsible for the material strength development. The properties described by this time-dependent criterion are those undrained since the backfilled mine stopes have been categorised as undrained in long term.

\section{Introduction}

Cemented paste backfill (CPB) is increasingly used in many mines throughout the world and has become more popular over the last decade. Many scientific aspects of laboratory-prepared CPBs (chemical, hydromechanical, micro-structural, rheological, and stability design) have been studied by several authors. A limited number of investigations have been conducted at meso-scale, large-scale and in situ (Ouellet and Servant, 2000; Hassani et al., 2004; Cayouette, 2003; Harvey, 2004; Belem et al., 2004, 2006; le Roux et al., 2005; Grabinsky and Bawden, 2007) which would help for numerical modelling and better design of backfilled stopes. Most of the existing numerical codes or stability design methods do not consider the impact of cement addition to tailings and curing time on the evolution of different properties of CPB. Moreover, in most cases the CPB is simulated in geotechnical software as a simple soil, as tailings can be considered. Unfortunately, CPB cannot be studied properly without taking into account the time factor, binder type and content as it is a material whose evolutionary behaviour differs markedly from that of uncemented tailings material. Consequently, it is more than necessary that numerical codes can take into account time-dependence failure criteria to allow proper stability design and simulating the mechanical behaviour of backfilled stopes at short, medium or long term (in terms of curing time). To the authors' knowledge, such failure criterion does not exist across the literature. The main objective of this study is to propose a simple undrained failure criterion taking into account curing time and binder content in the CPB material.
\end{abstract}

\section{Background on cemented paste backfill}

\subsection{Overview of the CPB properties}

Freshly prepared $\mathrm{CPB}$ which can have initial void ratio $\mathrm{e}_{0}$ in the range $0.59-1.87$ (for specific gravity of tailings in the range 2.7-4.4) and solids mass concentration $C_{\mathrm{w}}$ ranging between $70 \mathrm{wt} \%$ (generally nonsulfidic tailings) and $82 \mathrm{wt} \%$ (sulfidic tailings), is fully saturated material. However, most hard rock mine tailings are classified as low-plastic silt (ML) and contain the minimum required $15 \mathrm{wt} \%$ of fine fraction (size $\leq 20 \mu \mathrm{m}$ ) which provides a high water retention potential when saturated. Once placed, self-weight consolidation takes place which results in the fill mass having slow drainage and minimal water bleed. The resultant settlement of saturated fresh backfill depends on rate of binder hydration (which is a function of the type of binder and its amount), the material's coefficient of consolidation $c_{\mathrm{v}}$, which combines permeability coefficient (or saturated hydraulic conductivity $k_{\text {sat }}$ ) and stiffness, and to the filling rate (Fourie et al., 2006; Fahey et al., 2009). Recent studies undertaken on the permeability behaviour of CPB show that for a given type of binder and its content, $k_{\text {sat }}$ decreases drastically between 0 and 3 days of curing by about one order of magnitude and remains nearly constant beyond this time (Godbout et al., 2007; Yilmaz et al., 2009). The drainage ability of emplaced fresh paste backfill depends mainly on the tailings fines content, its mineralogy (clay-like minerals content) and the binder type used. Indeed, an investigation into the characteristics of CPB 
self-weight consolidation using meso-scale columns shows that CPB prepared with ground granulated blast furnace slag (or GGBFS) blended binder drained more easily (which depends on the specific surface area or Blaine value) than CPB prepared with only general use (GU) Portland cement and sulphate-resistant (HS) Portland cement (El Aatar, 2009).

The low permeability of $\mathrm{CPB}$ confers the ability to remain or nearly remain fully saturated within the stope for long periods of time (lower rate of consolidation). In fact, field investigations confirm that the average long-term degree of saturation $S_{\mathrm{r}}$ of CPB varies between 80 and $95 \%$ over the age of 365 days (Cayouette, 2003; le Roux et al., 2005; Ouellet and Servant, 2000). A key issue in freshly emplaced CPB material is the excess pore water pressure ( $p w p$ ) build-up during filling. If some consolidation is allowed to occur during filling, the result is effective stress development within the paste backfill (Fahey et al., 2009). If no consolidation occurs, there would be a greater chance of developing excess pore water pressure in pastefill under compression. Following filling, the combined effects of chemical shrinkage (or self-desiccation) and subsequent water drainage will increase the effective stresses resulting in a reduction in vertical total stress at the base of the stope due to the development of arching (Fourie et al., 2007; Helinski et al., 2007a, 2007b, 2007c; Fahey et al., 2009; Li and Aubertin, 2009). From a geotechnical point of view, CPB is closer to controlled low-strength materials (CLSM) than a soil. The only real differences between these two materials are their slump height $S$ (152-254 $\mathrm{mm}$ for CPB and $\geq 254 \mathrm{~mm}$ for CLSM), water/cement ratio $w / c$ ( $\geq 3$ for $\mathrm{CPB}$ and $\leq 3$ for CLSM) and upper limit strength ( $8 \mathrm{MPa}$ for CLSM and $\leq 5 \mathrm{MPa}$ for CPB). Moreover, for polymetallic hard rock mines with sulfidic tailings, the CPB is often prepared with high sulfated water and therefore should be resistant to acid and sulphates attacks (property that CLSM does not possess). A different term could then be suggested to describe CPB and could be for example, 'controlled moderate strength tailings' (CMST).

\subsection{CPB drainage characteristics}

As seen above, the strength of soils (sand and clays) is expressed as the maximum resistance which they offer to deformation by applied stress. The strength characteristics of soils depend to some extent on their stress history and on the conditions under which they will be stressed in practice. Consequently, it can be somewhat difficult to directly apply classical soil mechanics concepts to CPB materials. The main challenge is the continuous change in all $\mathrm{CPB}$ physical and mechanical properties during curing due to cementation. For instance, with in situ placed $\mathrm{CPB}$, there is no notion of stress history apart from self-weight consolidation, eventually the squeezing effect of stope wall convergence and confined stress unloads during mining in adjacent stope. It should first be noted that once placed into a stope, the CPB does not suffer from surcharge loading during its lifetime, apart from overloads due to heavy vehicular traffic. The freshly emplaced paste backfill therefore primarily undergoes self-weight loading. While the UCS test is most popular for the characterisation of the compressive strength of $\mathrm{CPB}$, the fact remains that the most probable failure of the fill mass would be due to shear stresses. In this regard, shear strength is required to assess stability during CPB faces exposure in stoping operations and stability as a working floor. Therefore, UCS can be used as an undrained shear strength indicator.

\subsubsection{Characteristic time of CPB consolidation}

Under these considerations, which triaxial compression test would be suitable for CPB drainage condition? Is it that the $\mathrm{CPB}$ should be tested under drained or undrained conditions? The answer to this question lies in calculating the characteristic time $t_{\mathrm{c}}$ of the consolidation process (i.e. the time it takes to dissipate all of the excess pore pressures; $\mathrm{T}_{\mathrm{v}}=2$ for $\mathrm{U}=99.42 \%$ consolidation) which is given as follows:

$$
t_{c}=\frac{H_{d r}^{2}}{c_{v}} T_{v}=\frac{2 H_{d r}^{2}}{c_{v}}
$$

Where:

$\begin{array}{lll}H_{\mathrm{dr}} & = & \text { maximum length of drainage path }(\mathrm{m}) . \\ c_{\mathrm{v}} & = & \text { coefficient of consolidation of } \mathrm{CPB}\left(\mathrm{m}^{2} / \text { year }\right)\end{array}$ 
Potential for excess pore pressure development depends on characteristic time of the consolidation process $\left(t_{\mathrm{c}}\right)$ relative to the time it takes to apply the load. If the loading time is very large compared to $t_{\mathrm{c}}$, excess pore pressures will not develop, and hence loading is drained; if the loading time is very small compared to $t_{\mathrm{c}}$, excess pore pressures will develop, and hence loading is undrained; if the loading time is similar to $t_{\mathrm{c}}$, some excess pore pressures may develop, and hence loading is partly drained. To illustrate this, consider for example a freshly prepared paste backfill (0-day curing time) with $4.5 \mathrm{wt} \%$ of blended general use Portland cement GU and ground granulated blast furnace slag binder type (named GU-Slag@20:80wt\%) which have a corresponding $c_{\mathrm{v}}=8.15 \times 10^{-2} \mathrm{~cm}^{2} / \mathrm{s}$ (maximum effective consolidation stress was $400 \mathrm{kPa}$; taken from Yilmaz et al., 2009) and considering a backfilled stope with a height of $30 \mathrm{~m}$ (one-way drainage) and a supposed developed effective stress $\sigma_{\mathrm{v}}^{\prime}$ in the range $200-400 \mathrm{kPa}$ due to self-weight consolidation, it will take about seven years to dissipate all the excess pore pressures if no cementation took place after the CPB placement, which is not the case. In this case, the loading time corresponds to the duration of the stope filling and following filling until the end of the free drainage process, which will be rarely more than two weeks. It can be considered that this two weeks loading time is very small compared to the characteristic time of seven years. From self-weight consolidation tests using $3 \mathrm{~m}$ high meso-scale columns equipped with pore pressure transducers (capable of measuring positive and negative pore pressure) and filled with CPB prepared with $5 \mathrm{wt} \%$ of the binder type GU-Slag@50:50 wt $\%$ (tailings $\mathrm{G}_{\mathrm{s}}=3.76$ and $44 \mathrm{wt} \%$ of grains size lower than $20 \mu \mathrm{m})$, it was observed that pore pressures dissipate $\left(u_{\mathrm{w}}=0\right)$ after elapsed time of 30-50 days after the end of filling the columns (El Aatar, 2009). The calculated characteristic time for the $3 \mathrm{~m}$ high columns based on Equation (1) and considering an effective stress $\sigma_{\mathrm{v}}^{\prime}$ of $44 \mathrm{kPa}$ along with a predicted corresponding $c_{\mathrm{v}}\left(\approx 8.83 \times 10^{-3} \mathrm{~cm}^{2} / \mathrm{s}\right)$ is about 0.65 year $(\approx 7.76$ months or 236 days $)$. Compared to the observed 50 days, it took less than quarter that time.

\subsubsection{Some aspects on CPB pore pressures dissipation}

It was also observed from the column tests that beyond the range of 30-50 days, negative pore pressures (suction $s$ ) were developed ( $-45 \mathrm{kPa}$ to $-80 \mathrm{kPa}$ depending on the binder type). The positive pore pressure $u_{\mathrm{w}}$ developed in all columns was identical and about $20 \mathrm{kPa}$ only (self-weight governing process) which is less than half of the measured suctions $s$. It was also observed from undrained laboratory tests (Fourie et al., 2006; Helinski et al., 2007b) that by backpressuring CPB and hydraulic fill samples containing $5 \mathrm{wt} \%$ binder up to $500 \mathrm{kPa}\left(u_{\mathrm{w}}\right)$, the phenomenon of chemical shrinkage (called self-desiccation) reduced the pore pressures after 65 hours by about 32\% for CPB and $64 \%$ for hydraulic fill. For the column tests, the end of drainage was observed between 60 and 72 hours (Belem et al., 2006; El Aatar, 2009). 


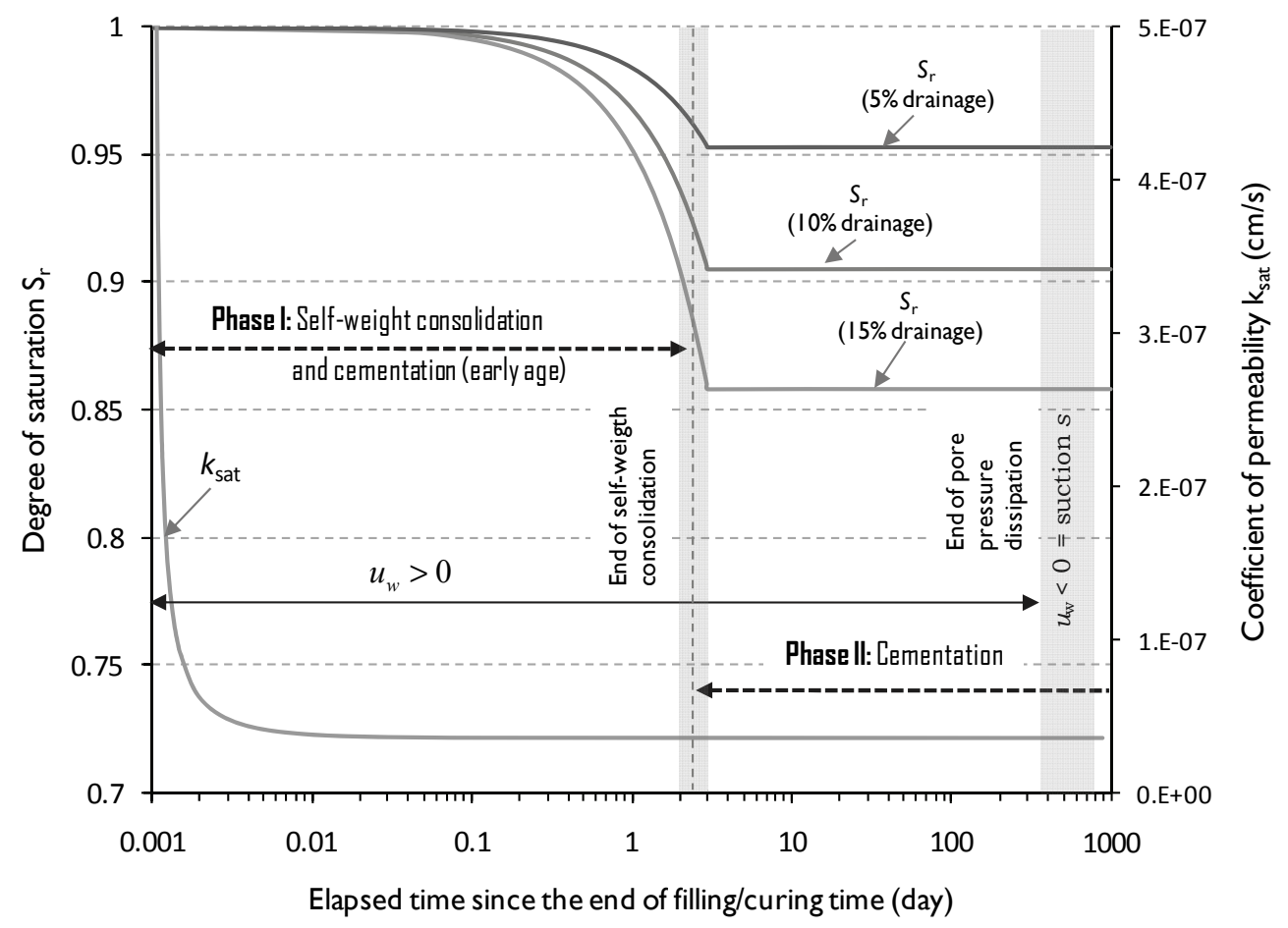

\section{Figure 1 Conceptual diagram showing the drainage properties of cemented paste backfill (for particular tailings: $\mathrm{Gs}=3.76$ and $44 \mathrm{wt} \%$ of fines content)}

This could partly explain why the dissipation time is considerably reduced in the CPB compared to calculated characteristic time $t_{\mathrm{c}}$, and thus confirms that the pore pressures development process in CPB is quite different from a natural soil or tailings. Consequently, excess pore pressures will develop and backfilled stopes must be considered as undrained systems for short-term stability analysis (based on pore pressure dissipation). In terms of saturation, it was previously mentioned that the degree of saturation $S_{\mathrm{r}}$ of CPB ranges roughly between 80 and $95 \%$ for long periods of time (after placement and full drainage). Indeed, from self-weight consolidation tests using $3 \mathrm{~m}$ high columns filled with in situ CPB, it was observed that 5 to $15 \%$ (corresponding to $4-5 \%$ of volumetric deformation) of the total water drains after between 60 and 72 hours (Belem et al., 2006; El Aatar, 2009). These results are very consistent with the observed range of field CPB degrees of saturation (le Roux et al., 2005). By collecting all these observations, it is possible to construct a single semi-log graphical model showing the theoretical drainage properties of paste backfill in general. Figure 1 shows this conceptual diagram for a particular tailings sample.

\subsection{CPB shear strength characteristics}

As stated by le Roux et al. (2005), understanding even the measured in situ stress distribution is complicated because there are several contributing factors that can influence the stress that develops in CPB. Typically, CPB is placed into an open stope for which full wall convergence has been achieved (already de-stressed) and, therefore, the stress regime in the CPB is mostly governed by self-weight (overburden pressure) and can be influenced by the stope geometry (arching effect). Consequently, the stress is expected to increase with an increase in overburden so that higher stress is experienced near the base of the stope than near the top of the stope (le Roux et al., 2005). Indeed, self-boring pressure metre (SBP) tests performed on in situ CPB in two different mines in Canada confirm that the minimum undrained stress (or minor principal stress $\sigma_{3}$ ) is close to the overburden pressure (Ouellet and Servant, 2000; le Roux et al., 2005). Moreover, the unloadingreloading loops conducted during in situ SBP tests by the same authors provided the evidence that CPB response is best described as undrained in terms of saturated soils mechanics (because $\sigma_{\text {average was found to }}$ be constant in these loops). But, it should be mentioned that the range of degree of saturation of tested backfilled stopes was $80-95 \%$. 
In terms of stress analysis, it is apparent from Figure 1 that during Phase I (the self-weight consolidation and cementation stage) the stress distribution within the CPB must be analysed on the basis of effective stresses $\left(\sigma^{\prime}=\sigma-u_{\mathrm{w}}\right)$. This will represent a very short term (early age) behaviour occurring during filling, but which will influence the subsequent strength development process. Starting from Phase II (cementation and chemical secondary reactions), however, the CPB is in undrained condition (based on saturated soils mechanics). However, the effective stress analysis could easily be extended in this phase to the time from which the excess pore pressures are expected to fully dissipate (characteristic time). This characteristic time will depend on the type of CPB and stope conditions and was estimated to be between 370-619 days based on column test data with a correction factor of 12.38 for scale effect (see Figure 1). Nevertheless, during Phase II the CPB behaves like a slow internal drying soil (development of suction, heat generated by binder hydration and ambient air). In these conditions, an appropriate stress analysis in Phase II would be that dedicated to partially saturated soils (Bishop et al., 1960; Fredlund et al., 1978), because application of $\sigma^{\prime}=\sigma-u_{\mathrm{w}}$ to partially saturated materials such as CPB can be appreciably in error (Skempton, 1960).

In terms of unconfined compressive strength (UCS) behaviour, it was widely observed that the laboratoryprepared material seems to underestimate the actual field strength (Cayouette, 2003; Revell, 2004). This seems to be mainly due to the CPB consolidation after placement. Consolidation gives rise to an increase in effective stress and increased the UCS by a factor up to 2.4 or a difference of up to $58 \%$ compared to the UCS obtained from undrained plastic mould samples, depending on height of fill, rate of rise, type of binder and its proportion (Rotta et al., 2003; Consoli et al., 2006; Fourie et al., 2006; Helinski et al., 2006, 2007a, 2007b, 2007c; Yilmaz et al., 2008, 2009). From self-weight consolidation tests on CPB materials using meso-scale columns ( $3 \mathrm{~m}$ high) it was observed that the UCS of undrained lab-prepared CPB samples matched the UCS of column-top samples, while the UCS of self-weight consolidated (drained) lab-prepared samples matched the UCS of column-bottom samples (Thakur, 2008; El Aatar, 2009). So, a design process using undrained lab-prepared CPB strength will be conservative as it is representative of the top of a stope only, while a design using self-weight consolidated (or drained) lab-prepared CPB strength will be less conservative as it is representative of the bottom of a stope.

To get the drained shear strength parameters $c^{\prime}$ and $\phi^{\prime}$, CID and CIU (with pore pressure measurement) triaxial tests must be performed. However, le Roux et al. (2005) show that the degree of saturation has a significant effect on the shear strength parameters of CPB whether it is field (more pronounced) or laboratory prepared. They suggest that backpressuring CPB test samples prior to testing (for saturation) can result in a significant difference in the response of the material and the prediction of its stability in the field. It appears that the CPB cannot be treated directly as a soil. Ultimately, its mechanical properties may be qualitatively comparable to those of over consolidated (OC) clays. If OC clays may exhibit effective cohesion $c^{\prime}$ due to particles having been forced into very intimate contact (due to colloidal forces) and that the quality of measured data remains questionable, in the case of CPB the existence of effective cohesion is undoubtedly due to inter-granular contacts and cement bonding. If soils are frictional materials, CPBs are cohesive and frictional materials. In total stress analysis purpose, the undrained cohesion $c_{\mathrm{u}}$ is the undrained shear strength $s_{\mathrm{u}}$ (for short term stability analysis) as in conventional soil mechanics the undrained angle of friction $\phi_{\mathrm{u}}=0$ (by definition) because the test samples must be fully saturated (even if this is not the case for CPB).

\section{Conventional compression tests on CPB}

\subsection{Cemented paste backfill mixtures preparation}

Four tailings samples were taken from four different Canadian mines (LVT, HMO, LRD and DYN) for laboratory preparation of paste backfill mixtures. Four types of binder were also used: a slag blended binder (a blend of general use GU Portland cement and slag; GU-Slag@20:80), fly ash blended binder (a blend of GU and fly ash; GU-FA@50:50), GU only and a blend of Portland cements (GU and sulphate resistant cement HS; GU-HS@50:50). The final mixtures solids content were $78 \mathrm{wt} \%$ for mines LVT and LRD $\left(\mathrm{G}_{\mathrm{s}-\mathrm{t}}\right.$ of tailings $=3.3$ and 3.8 for LVT and LRD respectively $), 74 \mathrm{wt} \%$ for mine $\operatorname{HMO}\left(\mathrm{G}_{\mathrm{s}-\mathrm{t}}=2.9\right)$ and $70 \mathrm{wt} \%$ for mine DYN $\left(\mathrm{G}_{\mathrm{s}-\mathrm{t}}=2.73\right)$. 


\subsection{Industrial unconfined compression tests}

After the target curing times, CPB specimens were subjected to uniaxial compression tests using a servo and computer controlled MTS testing machine (model 10/GL load frame) with a $50 \mathrm{kN}$ loading capacity. Each sample was broken at a constant deformation rate of $1 \mathrm{~mm} / \mathrm{min}$. The UCS value corresponds to the maximum stress value (failure peak) reached during the compression tests. As will be discussed in the discussion section, this simplest way to get UCS values as CPB strength parameter can be somewhat questionable due to suction induced within the samples during compression test due to some dilation (Simms and Grabinsky, 2009).

Table 1 CIU testing parameters

\begin{tabular}{llll}
\hline Type of CPB & Type of Binder & $\begin{array}{l}\text { Curing } \\
\text { Time } \boldsymbol{t} \\
\text { (day) }\end{array}$ & $\begin{array}{l}\text { Range of } \\
\text { Confining } \\
\text { Pressure } \boldsymbol{\sigma}_{3} \\
\text { (kPa) }\end{array}$ \\
\hline Lab-prepared: mine LVT & GU-Slag & 118 & $250-500$ \\
Lab-prepared: mine LVT & GU-Slag & 111 & $600-1,200$ \\
Lab-prepared: mine LVT & GU-Slag & 118 & $700-1,600$ \\
Lab-prepared: mine HMO & GU-Slag & 109 & $400-800$ \\
Lab-prepared: mine HMO & GU-HS & 123 & $125-250$ \\
Lab-prepared: mine HMO & GU-Fly Ash C & 123 & $150-300$ \\
Lab-prepared: mine LRD & GU-HS & 111 & $200-800$ \\
Lab-prepared: mine LRD & GU-Fly Ash C & 135 & $200-800$ \\
In situ-prepared: mine DYN & GU & 47 & $100-200$ \\
In situ-prepared: mine DYN & GU & 41 & $100-200$ \\
In situ-prepared: mine LVT e & GU-Slag & 113 & $200-800$ \\
In situ-prepared: mine LVT & GU-Slag & 157 & $200-800$ \\
In situ-prepared: mine LVT & GU-Slag & 605 & $200-800$ \\
\hline
\end{tabular}

\subsection{Consolidated undrained triaxial compression tests}

For each CPB mixtures, isotropically consolidated-undrained (CIU) tests were performed at a constant deformation rate of $0.5 \mathrm{~mm} / \mathrm{min}$ using the same MTS testing equipment. Additional in situ CPB core samples taken from the mine LVT (4.5wt\% of binder type GU-Slag@20:80) were also tested. During these tests, our samples were not back-saturated in order to reliably reproduce the same conditions as in situ. Unfortunately, the pore pressures were not measured during these tests. It should be recalled that in conventional soils mechanics the test samples should be saturated (or back-saturated) but this may not be a similar condition than in situ. Table 1 above contains the CIU test parameters.

\section{$4 \quad$ Results}

\subsection{Unconfined and confined compression test results}

Table 2 contains the values of UCS and undrained cohesion $c_{\mathrm{u}}$ (intercept values) obtained from triaxial CIU tests on different CPB mixtures (Belem et al., 2000). 
Table 2 UCS and undrained cohesion data for the different paste backfill mixtures

\begin{tabular}{llllll}
\hline $\begin{array}{l}\text { Type of } \\
\text { CPB }\end{array}$ & $\begin{array}{l}\text { Type of } \\
\text { Binder }\end{array}$ & $\begin{array}{l}\text { Curing } \\
\text { Time } \boldsymbol{t} \\
(\mathbf{d a y})\end{array}$ & $\begin{array}{l}\text { Binder } \\
\text { Content } \boldsymbol{B}_{\mathbf{w}} \\
\mathbf{( w t \% )}\end{array}$ & $\begin{array}{l}\text { UCS } \\
(\mathbf{k P a})\end{array}$ & $\begin{array}{l}\text { Measured } \mathbf{c}_{\mathbf{u}} \\
\mathbf{( k P a )}\end{array}$ \\
\hline Mine LVT & GU-Slag & 118 & 3 & 1,031 & 401 \\
Mine LVT & GU-Slag & 111 & 4.5 & 2,367 & 1,028 \\
Mine LVT & GU-Slag & 118 & 6 & 3,524 & 1,663 \\
Mine HMO & GU-Slag & 109 & 4.5 & 1,288 & 529 \\
Mine HMO & GU-HS & 123 & 4.5 & 526 & 158 \\
Mine HMO & GU-Fly Ash C & 123 & 4.5 & 798 & 250 \\
Mine LRD & GU-HS & 111 & 4.5 & 1,091 & 467 \\
Mine LRD & GU-Fly Ash C & 135 & 6 & 1,229 & 405 \\
Mine DYN & GU & 47 & 3 & 227 & 62 \\
Mine DYN & GU & 41 & 7 & 432 & 116 \\
Mine LVT e & GU-Slag & 113 & 4.5 & 1,471 & 396 \\
Mine LVT & GU-Slag & 157 & 4.5 & 3,185 & 1,405 \\
Mine LVT & GU-Slag & 605 & 4.5 & 2,991 & 959 \\
\hline
\end{tabular}

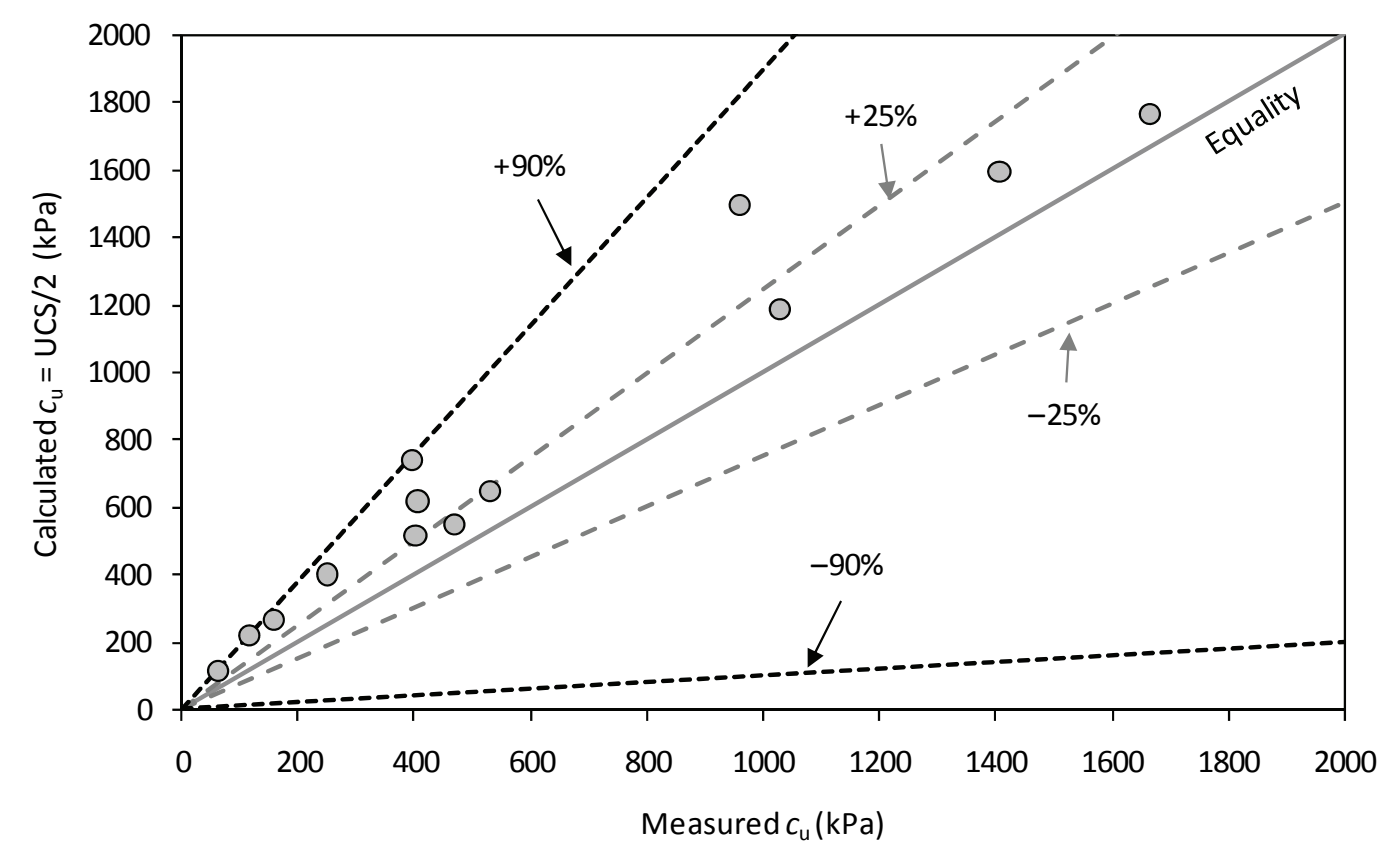

Figure 2 Comparison of laboratory measured undrained cohesion $c_{\mathrm{u}}$ and calculated $c_{\mathrm{u}}(=\mathrm{UCS} / 2)$

Figure 2 presents a comparison of measured undrained cohesion $c_{\mathrm{u}}$ from triaxial CIU tests (intercept values) and calculated $c_{\mathrm{u}}=\mathrm{UCS} / 2$ values. This figure shows that only $46 \%$ of the experimental data fall in the $\pm 25 \%$ range ( $75 \%$ confidence limit), while all data fall in the $\pm 90 \%$ range (only $10 \%$ confidence limit). That would mean that for paste backfill, the approximation of $c_{\mathrm{u}}=\mathrm{UCS} / 2$ could be used with only $10 \%$ confidence. An alternative solution to improve the confidence limit would be to propose an empirical model for predicting $c_{\mathrm{u}}$ from UCS. In fact, if the undrained cohesion $c_{\mathrm{u}}$ can be predicted with curing time $t$, binder proportion 
$B_{\mathrm{w}},\left(=100 \times \mathrm{M}_{\text {binder }} / \mathrm{M}_{\text {dry tailings }}\right)$, then the shear strength $\left(s_{\mathrm{u}}=c_{\mathrm{u}}\right)$ can automatically be determined. The advantage of using UCS as a starting parameter is that it can indirectly take into account the type of binder and stope depth $h$. Indeed, in situ CPB core samples UCS data (Cayouette, 2003; le Roux et al., 2005) revealed that its variation follow the overburden total stress $\left(\sigma_{\mathrm{v}}=\gamma h, h=\mathrm{depth}\right)$. But this is due to combine effects of self-weight consolidation (increased solids content/relative density and reduced void ratio), cementation (void ratio reduction), self-desiccation (pore pressure reduction and increased effective stress) and the rate of filling (loading process). Figure 3 is an illustration of UCS increase with stope depth.

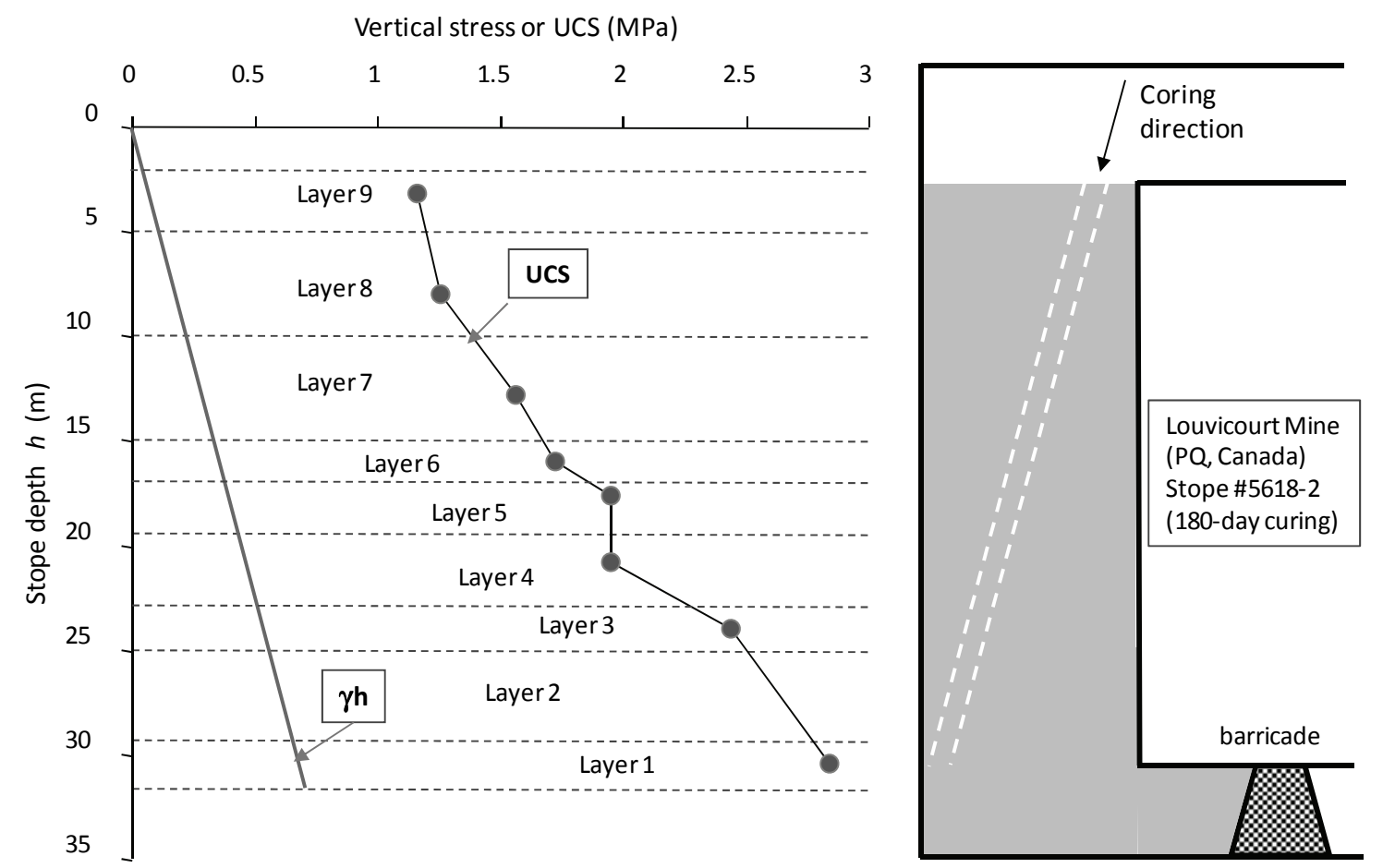

Figure 3 Variation in Louvicourt Mine in situ paste backfill UCS with the stope depth (adapted from Cayouette, 2003)

Since UCS varies with depth $h$ and $c_{\mathrm{u}}$ value is related to UCS value, it follows that the variation in $c_{\mathrm{u}}$ should be mandatory also with depth $h$. The prediction of $c_{\mathrm{u}}(h)$ as a function of $\operatorname{UCS}(h)$ will thus allow to better perform short-term stability analysis of exposed paste backfill faces (for long-term stability analysis, the effective shear strength parameters should be used). In this context it should be noted that it is not necessary to predict $\mathrm{UCS}(h)$ since the CPB can be designed to simulate depth effect using effective stress curing (Helinski et al., 2007b; Yilmaz et al., 2009). Of course, the UCS obtained from paste backfill core samples corresponds to a given depth $h$. The UCS variation with stope depth means that a backfilled stope can be considered as consisting of several 'equivalent layers', each having its single UCS value (and therefore its single $c_{\mathrm{u}}$ value) as shown in Figure 3. When a stope face is exposed over a height $H_{\mathrm{e}}$, the short-term design criteria should take into account the undrained shear strength developed in the CPB at this depth $\left(h=H_{\mathrm{e}}\right)$. The general trend of UCS with stope depth can be approximated by a linear relationship given as follows:

$$
U C S(h)=U C S_{0}+\lambda \gamma_{w e t} h=U C S_{0}+\lambda\left(\frac{\gamma_{d}}{C_{w}}\right) h=U C S_{0}+\lambda\left(\frac{\gamma_{s}}{C_{w}(1+e)}\right) h
$$

where $U C S_{0}=$ top-stope UCS value (or value obtained from laboratory-prepared undrained mould samples UCS), $\lambda=$ scaling scalar, $\gamma_{\text {wet }}=$ total or wet unit weight of CPB $\left(\mathrm{kN} / \mathrm{m}^{3}\right), \gamma_{\mathrm{d}}=$ dry unit weight of CPB $\left(\mathrm{kN} / \mathrm{m}^{3}\right), \gamma_{\mathrm{s}}=$ specific unit weight of CPB $\left(\mathrm{kN} / \mathrm{m}^{3}\right), C_{\mathrm{w}}=$ fractional solid mass concentration of CPB (unitless), $e=$ void ratio of $\mathrm{CPB}, h=$ backfilled stope depth (m). From in situ and meso-scale column backfill UCS data it was found that $\lambda$ is around 3 . 


\subsection{Time-dependent undrained shear strength failure criterion}

\subsubsection{Predictive models for undrained cohesion of CPB}

Since it was observed that the undrained angle of friction $\phi_{\mathrm{u}}$ of CPBs was not zero probably due to suction induced during testing (Simms and Grabinsky, 2009), this means that the undrained cohesion $c_{\mathrm{u}}$ will vary with stope depth and is expected to be slightly different than the half of UCS ( $\left.c_{\mathrm{u}} \neq \mathrm{UCS} / 2\right)$ as it should be in conventional saturated soils mechanics $\left(c_{\mathrm{u}}=\mathrm{UCS} / 2\right)$. Figure $4 \mathrm{a}$ shows the direct relationship between $c_{\mathrm{u}}$ (in $\mathrm{kPa}$ ) and UCS (in $\mathrm{kPa}$ ) which is well fitted with a power law function with high coefficient of correlation $(r=0.993)$ and given as follows:

$$
c_{u}=0.087 \cdot(U C S)^{1.1978}
$$

Equation (3) could be used to predict $c_{\mathrm{u}}$ of CPB material when the curing time $t$ and the initial binder content $B_{\mathrm{w}}$ are unknown and it was assumed that any UCS value is assigned to a given stope depth $h$ within the emplaced CPB, UCS $(h)$.
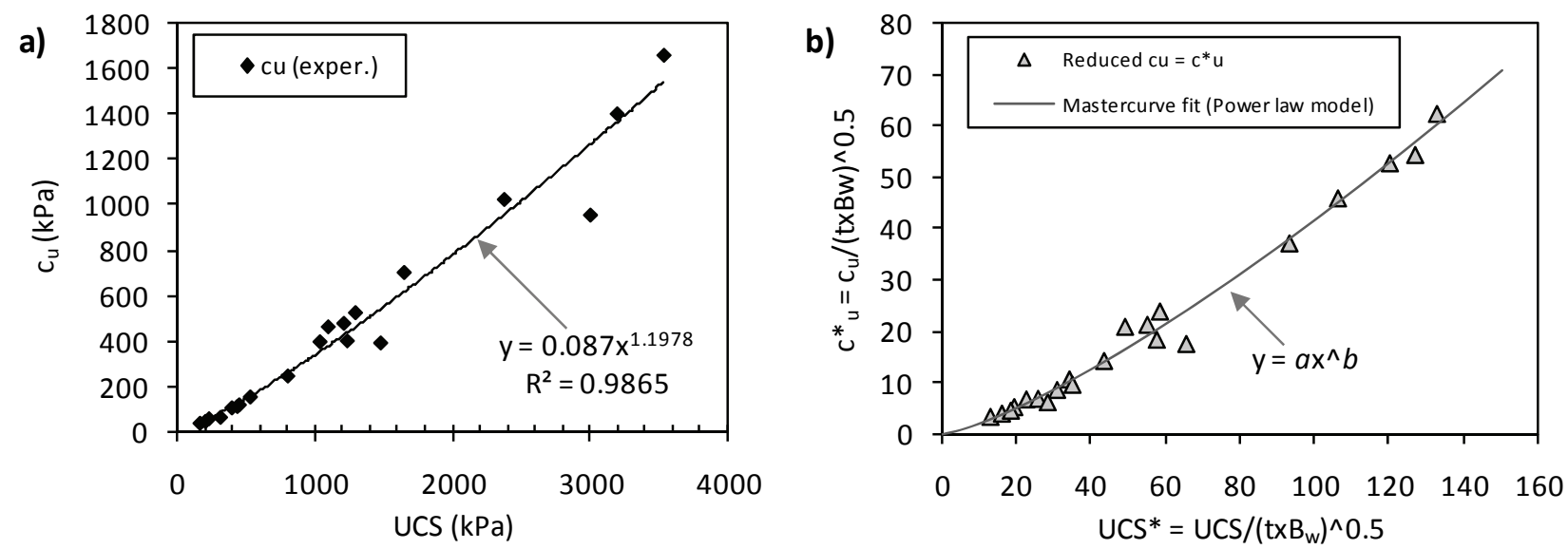

Figure 4 Variation in CPB undrained cohesion $c_{\mathrm{u}}$ with UCS: a) direct relationship, b) reduced variables $c^{*}$ and $U C S^{*}$ relationship

It should be recalled that CPB strength is an intimate function of binder type, binder content and curing time. As we already assumed that the binder type is capture through the UCS value (even if it captures also the effect of $t$ and $B_{\mathrm{w}}$ ) in a phenomenological manner, it remains two dependant variables to be incorporated in another predictive model, namely the curing time $t$ and the binder content $B_{\mathrm{w}}$. Therefore, variables reduction is necessary as it was not considered relevant to perform a stepwise multiple regression analysis.

For that purpose, the dependent variable UCS and the independent variable $c_{\mathrm{u}}$ are reduced $\left(U C S^{*}, c^{*}{ }_{\mathrm{u}}\right)$ by a shift factor $a_{\mathrm{c}}=\left(t \times B_{\mathrm{w}}\right)^{0.5}$ as follows: $X=U C S^{*}=\mathrm{UCS} / a_{\mathrm{c}}$ and $Y=c^{*}{ }_{\mathrm{u}}=c_{\mathrm{u}} / a_{\mathrm{c}}$. Figure $4 \mathrm{~b}$ is a plot of $c^{*}{ }_{\mathrm{u}}$ as a function of $U C S^{*}$. It can be observed that the reduced variables are also very well fitted by a power law model (mastercurve) which is given as follows:

$$
\begin{gathered}
c_{u}^{*}=0.10696 \cdot\left(U C S^{*}\right)^{1.2995} \\
\frac{c_{u}}{\sqrt{t \cdot B_{w}}}=0.10696 \cdot\left(\frac{U C S}{\sqrt{t \cdot B_{w}}}\right)^{1.2995}
\end{gathered}
$$

Rearranging Equation (4b) yields the general empirical predictive model for undrained cohesion $c_{\mathrm{u}}$ (in $\mathrm{kPa}$ ) as a function of UCS (in $\mathrm{kPa}$ ), curing time $t$ (in days) and binder content $B_{\mathrm{w}}(\mathrm{wt} \%)$ as follows:

$$
c_{u}\left(t, B_{w}\right)_{k P a}=a \cdot(U C S)^{b} \cdot\left(t \cdot B_{w}\right)^{-c}
$$


where $a, b$ and $c$ are CPB constants or fitting parameters. For the range of binder content $2-7 \mathrm{wt} \%$ and curing times of 1-605 days, the value of fitting parameters are: $a=0.10696, b=1.2995$ and $c=0.14975$ with a coefficient of correlation $r=0.993$.
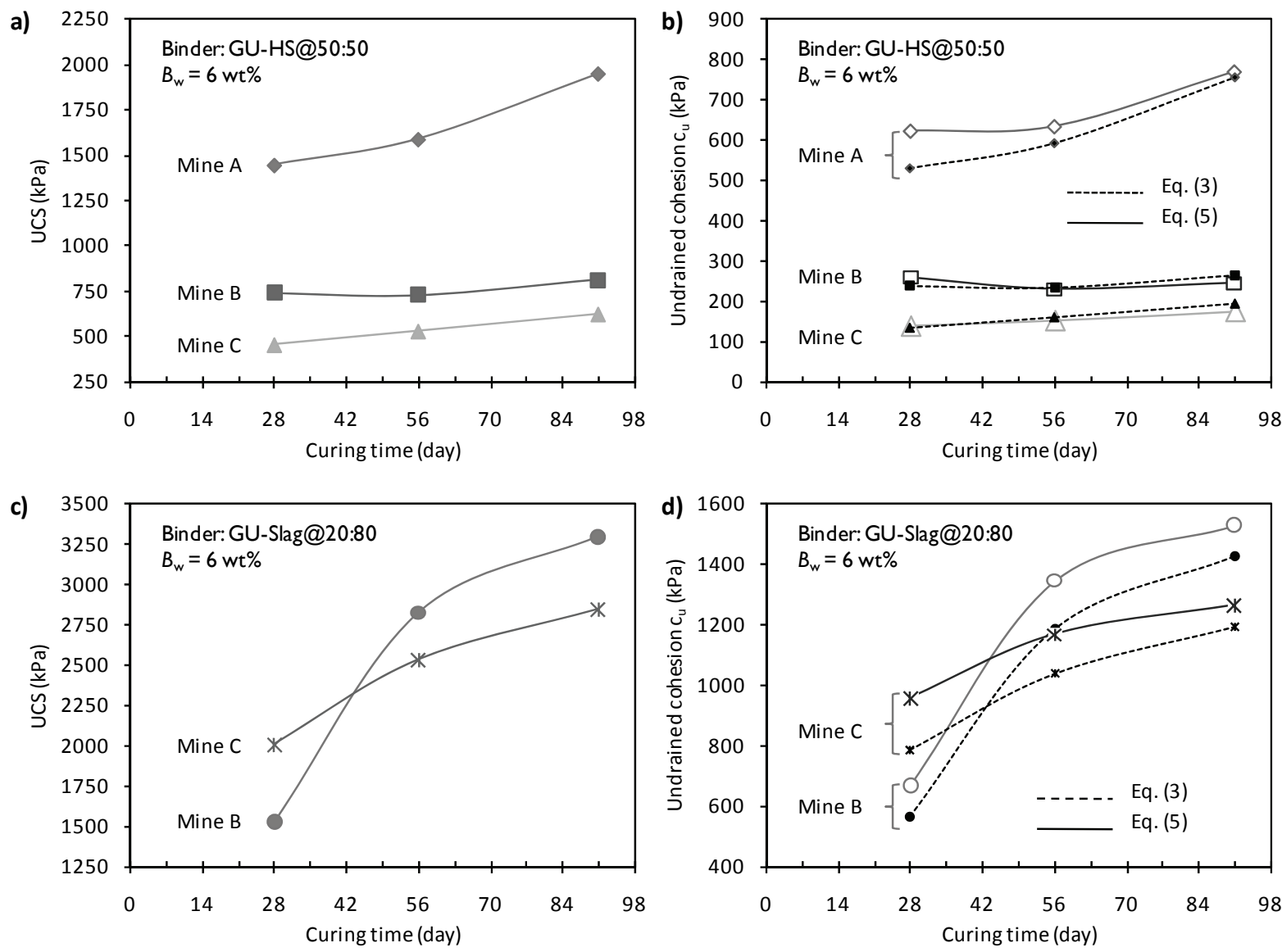

Figure 5 Variation in backfill UCS and undrained cohesion $c_{\mathrm{u}}$ with curing time: a) UCS values with GU-HS@50:50 binder, b) predicted $c_{\mathrm{u}}$ for GU-HS@50:50 binder, c) UCS values with GU-Slag@20:80 binder, d) predicted $c_{\mathrm{u}}$ for GU-Slag@20:80 binder

If the binder content $B_{\mathrm{w}}$ and the curing time $t$ are known as well as UCS, Equation (5) should be used instead of Equation (3) in order to get more accurate predicted values. Figure 5 presents a sample application of Equations (3) and (5) on UCS data from three different mine backfills prepared with two different types of binder(GU-HS@50:50 and GU-Slag@20:80) at a constant binder content of 6 wt\% (UCS data taken from Benzaazoua et al., 2000). From this figure, it can be observed that a little difference exists between Equation (3) and Equation (5) in predicted $c_{\mathrm{u}}$ values.

\subsubsection{Validation of the empirical fitting models}

Since the time-dependent failure criterion will depend mainly on the accuracy of predicted $c_{\mathrm{u}}$, it is necessary to validate the proposed models (Equations (3) and (5)). Unfortunately, there is not much data available in the literature on triaxial test results on CPBs. Except from the CIU test results presented in the present study, other CIU test results without pore pressure measurement have been carried out and reported in the literature (Lampron, 2000; Cayouette, 2003). Rankine and Sivakugan (2007) also reported some triaxial UU and CID test results on two types of CPB while some additional CID and CIU $+u$ test results (drained or effective parameters) are also reported (le Roux et al., 2005). From all data collected, those including UCS values only can be used for predicting $c_{\mathrm{u}}$ using Equations (3) and (5). Figure 6 presents a comparison between measured and predicted cohesion for CPB materials. It can be observed that the undrained cohesion $c_{\mathrm{u}}$ is satisfactorily predicted using Equations (3) and (5). From this figure it can be also concluded that Equations (3) and (5) can be used for predicting the undrained cohesion $c_{\mathrm{u}}$ of CPB with at least $85 \%$ of confidence $( \pm 15 \%$ range). 


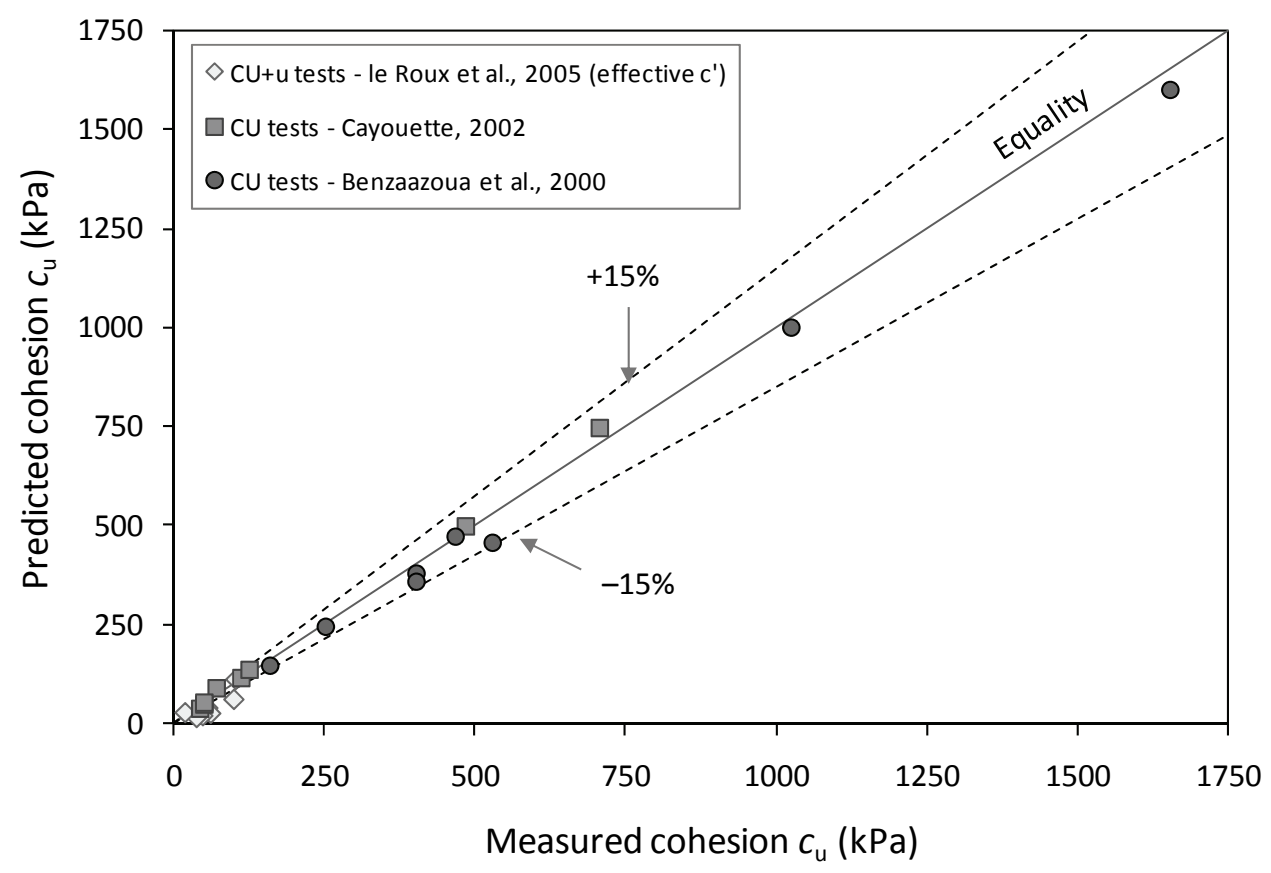

Figure 6 Comparison of predicted and measured cohesion for different CPB mixture data taken from the literature

\subsubsection{Time-dependent undrained shear strength}

Now that the Equations (3) and (5) can be used with at least $85 \%$ of confidence to predict the undrained cohesion $c_{\mathrm{u}}$, the undrained time-dependent failure criterion (UTDFC) may then be defined as a function of curing time $t$ and binder content $B_{\mathrm{w}}$ and is given as follows:

$$
\tau_{f}\left(t, B_{w}\right)=s_{u}\left(t, B_{w}\right)=c_{u}\left(t, B_{w}\right)
$$

Substituting Equation (5) into Equation (6) yields the final form of the time-dependent undrained failure criteria for CPB materials (each UCS value must be attributed to a given depth $h$ within a backfilled stope):

$$
s_{u}\left(t, B_{w}\right)=0.10696 \cdot(U C S)^{1.2995} \cdot\left(t \cdot B_{w}\right)^{-0.14975}
$$

Or in terms of principal stresses:

$$
\sigma_{1}^{\prime}-\sigma_{3}^{\prime}=\sigma_{1}-\sigma_{3}=2 c_{u}\left(t, B_{w}\right)=2 s_{u}\left(t, B_{w}\right)
$$

where $\sigma_{1}^{\prime}=$ effective major principal stress $\left(\mathrm{N} / \mathrm{m}^{2}\right), \sigma_{3}^{\prime}=$ effective minor principal stress $\left(\mathrm{N} / \mathrm{m}^{2}\right), \sigma_{1}=$ major principal stress $\left(\mathrm{N} / \mathrm{m}^{2}\right), \sigma_{3}=$ minor principal stress $\left(\mathrm{N} / \mathrm{m}^{2}\right)$. 

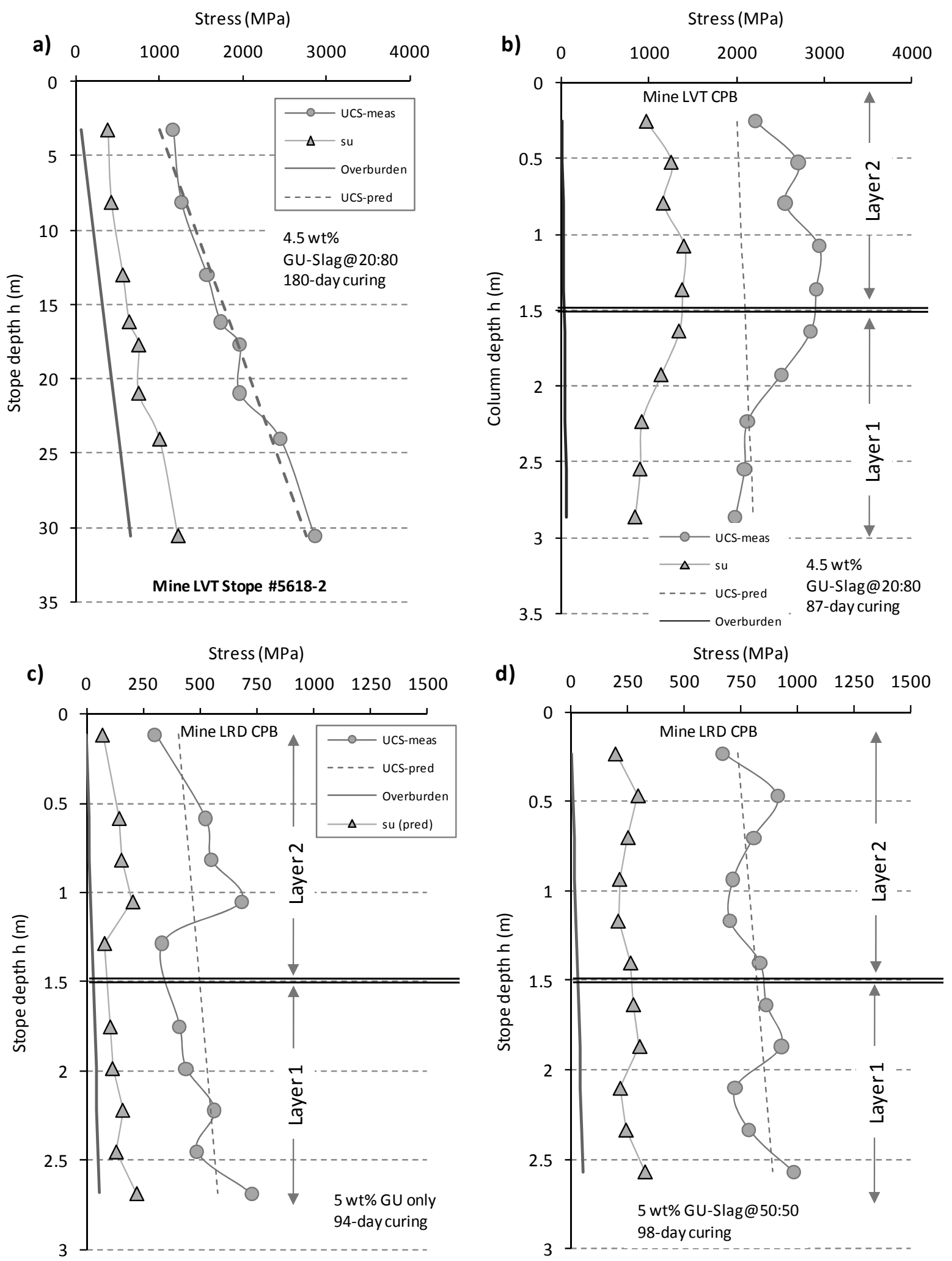

Figure 7 Different undrained shear strength profiles calculated from the UCS values: a) for mine LVT stope CPB data, b) for $3 \mathrm{~m}$ high columns test using mine LVT CPB, c) for columns test with mine LRD CPB, d) for columns test with mine LRD CPB 


\subsubsection{Sample application}

Figure 7 presents a sample application of Equation (7) to depth-dependent data obtained from in situ CPB core samples and $3 \mathrm{~m}$ high columns CPB samples. The UCS values from columns CPB were obtained on core samples taken at different depths at the end of curing. It is important to note that each of the three columns in Figure 7 were filled in two layers within 24 hours, that is to say 12 hours per layer (filling rate of $0.125 \mathrm{~m} /$ hour). In Figure 7 the dotted lines represent the estimated UCS profiles (UCS versus depth $h$ ) using Equation (2). It should be noted that this equation is useful only for a rough estimate of the UCS profile in a backfilled stop. Overall, this estimate is satisfactory in a preliminary investigation point of view. As expected, it can be observed that the $s_{\mathrm{u}}$ profiles follow the UCS profiles. From Figure 7a it can be seen that the trend of in situ data follows clearly the overburden stress while in the case of columns CPB data this trend is not so clear (Figures $7 \mathrm{~b}, \mathrm{c}$ and $\mathrm{d}$ ). This difference in trend is probably due to a scale effect and the columns filling sequences. Figure $7 \mathrm{~b}$ show lowest UCS and $s_{\mathrm{u}}$ values at the bottom of the columns mainly due to a highest degree of saturation (imperfect free drainage process). Indeed, the second layer (top) will drain its water through the first layer (bottom) after it was deposited 12 hours earlier. This can explain why this bottom layer (layer 1) has a higher degree of saturation. Figure 7c shows that for each layer, the UCS and $s_{\mathrm{u}}$ profiles increase linearly with depth (trend of the overburden stress) while in Figure $7 \mathrm{~d}$ this trend is not clear. It appears that the trend of UCS and $s_{\mathrm{u}}$ profiles depend also on the type of binder used (GU versus GU-Slag). The interest of $s_{\mathrm{u}}$ (or UCS) profiles is to have undrained shear strength values for different 'equivalent strata' within a backfilled stope. In this way, it is possible to calculate the stability of an exposed $\mathrm{CPB}$ face by taking into account the depth-dependency of undrained shear strength $s_{\mathrm{u}}$.

\section{Discussion}

As previously mentioned the CPB undrained shear strength development mainly depends on the early age self-weight consolidation (curing under effective stresses) and cementation (or hardening) process during the course of curing time. The end result is a reduction of the initial void ratio $e_{0}$ by the combined effect of densification and hardening. The effect of relative density can be quantified through the void ratio or solid mass concentration $C_{\mathrm{w} \%}$, while the hardening can be quantified by the water-cement $W / C$ ratio. In Equation (7), the binder content $B_{\mathrm{w} \%}$ can be expressed in terms of water-cement $W / C$ ratio and solid mass concentration $C_{\mathrm{w} \%}$ as follows:

$$
B_{w \%}=100\left(10^{2}-C_{w \%}\right) /\left[C_{w \%}(1+W / C)-100\right]
$$

In Equation (9) the solid mass concentration $C_{\mathrm{w} \%}$ can be expressed in terms of unit weights $\left(\gamma_{\mathrm{s}}\right.$ and $\left.\gamma_{\mathrm{wet}}\right)$, initial void ratio $e_{0}$ and volumetric solid concentration $C_{\mathrm{v} \%}$ as follows:

$$
C_{w \%}=100\left[\frac{\gamma_{s}}{\gamma_{w e t}}\left(\frac{1}{1+e_{0}}\right)\right]=100\left(\frac{\gamma_{s}}{\gamma_{\text {wet }}} \frac{C_{v \%}}{100}\right)
$$

Finally, by replacing Equations (9) and (10) into Equation (7) yields the following expression for $s_{\mathrm{u}}$ :

$$
s_{u\left(t, B_{w \%}\right)}=\alpha \cdot U C S^{\beta_{0}} \cdot\left(t\left[100\left(1-\frac{\gamma_{s}}{\gamma_{w e t}\left(1+e_{0}\right)}\right)\right] /\left[\frac{\gamma_{s}}{\gamma_{w e t}\left(1+e_{0}\right)}\left(1+\frac{W}{C}\right)-1\right]\right)^{-\beta_{1}}
$$

Where:

$\begin{array}{lll}\alpha, \beta_{0} \text { and } \beta_{1} & = & \mathrm{CPB} \text { material constants }\left(\text { here } \alpha=0.10696, \beta_{0}=1.2995 \text { and } \beta_{1}=0.14975\right) . \\ \gamma_{\text {wet }} & = & \text { total or wet unit weight of } \mathrm{CPB}\left(\mathrm{kN} / \mathrm{m}^{3}\right) . \\ \gamma_{\mathrm{s}} & = & \text { specific unit weight of } \mathrm{CPB}\left(\mathrm{kN} / \mathrm{m}^{3}\right) . \\ C_{\mathrm{v} \%} & \text { volumetric solid concentration of } \mathrm{CPB}(\%) . \\ e_{0} & = & \text { void ratio of CPB. }\end{array}$


It should be mentioned that a more complex column design option could have been adopted with perforated walls and geotextiles to simulate in situ stope walls drainage. However, as the observed rate of drainage and self-weight settlement matched the in situ data (Cayouette, 2003), it was considered that the adopted column lateral and bottom drainage configuration was reasonably acceptable. The choice of CIU tests for determination of undrained shear strength of CPB follows the recommendations of Ladd and Foott (1974) that $s_{\mathrm{u}}$ should be obtained from tests on reconsolidated samples using the test equipment and rate of loading which best reproduces the in situ stress and deformation conditions, using anisotropic consolidation if necessary to represent the initial shear stresses on potential failure planes in the field. But it should also be noted that the UCS and $c_{\mathrm{u}}$ parameters used in this study contain some uncertainties in their determination in terms of conventional soil mechanics. In effect, the CIU tests presented in this paper were carried out under CPB samples 'natural' saturation conditions. This choice was guided by the concern to remain close to in situ conditions which are that paste backfill is partially saturated. This is why the undrained cohesion $c_{\mathrm{u}}$ is not equal to half of the UCS as would have been. One of the main reasons for these results is the high suctions induced during the sample shearing which reduces the positive pore pressure. In addition, during the unconfined compression test, the peak value appears to be directly dictated by the suction induced at the samples failure due to dilatancy (Grabinsky and Simms, 2009). The question now is how to give meaning to UCS? The answer depends on what one wants to do with the UCS data. If UCS must be used for short-term stability analysis (short time face exposure, for example), then the UCS obtained with the effect of shearinduced suction still remains a good value because the paste backfill is expected to be partially saturated (between 80 and $95 \%$ degree of saturation). But for long-term stability analysis, the UCS obtained with the effect of shear-induced suction is not really a good parameter anymore because this suction affects (positively) the effective stress, and thus will induce a 'false' conservative factor of safety. If the use of UCS data has to be generalised, it is imperative to ensure that no suction can be generated during the unconfined compression tests. It is this type of approach that the authors of this paper are adopting while using either the concept of the effective stress curing (Fourie et al., 2006; Helinski et al., 2006, 2007a, 2007b, 2007c) or the unidimensional consolidation (Yilmaz et al., 2008, 2009).

\section{Conclusion}

This paper presents a simple time-dependent failure criterion (TDFC) developed to help improving the stability analysis of backfilled mine stopes. The main interest of this TDFC is that it takes into account the curing time and binder content. This simple failure criterion works on the undrained behaviour (short term) only of paste backfill. This choice was made based on the fact that cemented paste backfill is a mix of solid (tailings + cement bonds) and liquid (water) phases which will remain almost saturated for long periods of time. Proposed predictive models for the undrained cohesion constitute the basis of this time-dependent failure criterion. It was established that the proposed predictive models could be used with at least $85 \%$ of confidence to deduce the undrained shear strength for a given CPB by using the unconfined compressive strength (UCS) values is supposed to correspond to a given depth in a backfilled stope. This simple failure criterion could be implemented easily into numerical codes to allow taking into account the binder content and curing time effects when simulating the behaviour of cemented paste backfills.

\section{Acknowledgements}

This research project was financially supported by the IRSST and parts of FUQAT and NSERC funds. The authors gratefully acknowledge their support. The final part of this work was conducted at the School of Civil and Resource Engineering (the Faculty of Engineering, Computing and Mathematics) of The University of Western Australia which is acknowledged for their support.

\section{References}

Belem, T., Benzaazoua, M. and Bussière, B. (2000) Mechanical behaviour of cemented paste backfill, In Proceedings 53rd Canadian Geotechnical Conference, Montréal, pp. 373-380.

Belem, T., Harvey, A., Simon, R. and Aubertin, M. (2004) Measurement and prediction of internal stresses in an underground opening during its filling with cemented fill, In Proceedings 5th International Symposium on Ground support in Mining and Underground Construction, Australian Centre of Geomechanics, Perth, Australia, pp. 619-630. 
Belem, T., El Aatar, O., Bussière, B., Benzaazoua, M., Fall, M. and Yilmaz, E. (2006) Characterization of self-weight consolidated paste backfill, In Proceedings Ninth International Seminar on Paste and Thickened Tailings, R. Jewell, S. Lawson and P. Newman (eds), Australian Centre for Geomechanics, pp. 333-345.

Benzaazoua, M., Belem, T. and Jolette, D. (2000) Investigation de la stabilité chimique et son impact sur la résistance mécanique des remblais cimentés, Rapport scientifique IRSST R-260, 158 p.

Bishop, A.W., Alpan, I., Blight, G.E. and Donald, I.B. (1960) Factors controlling the strength of partly saturated cohesive soils, Conf. Shear Strength Cohesive Soils, American Society of Civil Engineers, New York, pp. 503-532.

Cayouette, J. (2003) Optimization of the paste backfill plant at Louvicourt mine, CIM Bulletin, pp. 51-57.

Consoli, N.C., Rotta, G.V. and Prietto, P.D.M. (2006) Yielding-compressibility-strength relationship for an artificially cemented soil cured under stress, Géotechnique, Vol. 56(1), pp. 69-72.

El Aatar, O. (2009) Étude de la consolidation des remblais miniers cimentés en colonnes, Thèse MScA. UQAT, 120 p.

Fahey M., Helinski M. and Fourie A. (2009). Some aspects of the mechanics of arching in backfilled stopes. Can. Geotech. J. 46(11), pp. 1322-1336.

Fourie, A.B., Fahey, H. and Helinski, M. (2007) Using effective stress theory to characterize the behaviour of backfill, CIM Bulletin, Vol. 100(1103), pp. 1-9.

Fourie, A., Helinski, M. and Fahey, M. (2006) Filling the gap - a geomechanics perspective, Australian Centre for Geomechanics Newsletter 26, Perth, Australia, pp. 1-4.

Fredlund, D.G., Morgenstern, N.R. and Widger, R.A. (1978) The shear strength of unsaturated soils, Canadian Geotechnical Journal, Vol. 15, pp. 313-321.

Godbout, J., Bussière, B., Aubertin, M. and Belem, T. (2007) Evolution of cemented paste backfill saturated hydraulic conductivity at early curing time, In Proceedings 60th Canadian Geotechnical Conf., Canada, 17 p.

Grabinsky, M.W. and Bawden, W.F. (2007) In situ Measurements for Geomechanical Design of Cemented Paste Backfill Systems, In Proceedings of Minefill 2007, Canadian Institute of Mining, Metallurgy and Petroleum (CIM), Montréal, Canada, paper No. 2456 [CD-ROM].

Harvey, A. (2004) Étude comparative des contraintes triaxiales dans le remblai en pâte selon la portée des chantiers, Mémoire de maîtrise ès sciences appliquées (génie minéral), École polytechnique Montréal, Canada, 136 p.

Hassani, F., Ouellet, J., Zhou, Z. and Roy, A. (2004) Paste backfill behaviour in a narrow vein mine: in situ stress and strain monitoring, In Proceedings 8th International Symposium on Mining with Backfill, Nonferrous Metals Society of China, Beijing, China, pp. 257-267.

Helinski, M., Fourie, A.B. and Fahey, M. (2006) Mechanics of early age cemented paste backfill, In Proceedings Ninth International Seminar on Paste and Thickened Tailings, Ireland, Vol. 9, pp. 313-322.

Helinski, M., Fourie, A.B., Fahey, F. and Ismail, M. (2007a) Assessment of the self-desiccation process in cemented mine backfills, Canadian Geotechnical Journal, Vol. 44(10), pp. 1148-1156.

Helinski, M., Fahey, H. and Fourie, A.B. (2007b) An effective stress approach to modelling mine backfilling, CIM Bull., Vol. 100, No. 1103, pp. 1-8.

Helinski, M., Fahey, F. and Fourie, A.B. (2007c) Numerical modelling of cemented paste backfill deposition, Journal of Geotechnical and Geoenvironmental Engineering, Vol. 13(10), pp. 1308-1319.

Ladd, C.C. and Foott, R. (1974) New design procedure for stability of soft clays, ASCE Journal of the Geotechnical Engineering Division, Vol. 100 (GT7), pp. 763-786.

Lampron, S. (2000) Excavation d'une galerie à travers le remblai en pâte à la Mine Louvicourt, Compte rendu du 15e Colloque en contrôle de terrain, Association minière du Québec, Val d'Or.

le Roux, K.A., Bawden, W.F. and Grabinsky, M.F. (2005) Field properties of cemented paste backfill at the Golden Giant mine, Mining Technology: Trans. of the Institute of Mining and Metallurgy, Section A, Vol. 114(2), pp. 65-80.

Li, L. and Aubertin, M. (2009) A three-dimensional analysis of the total and effective stresses in submerged backfilled stopes, Geotechnical and Geological Engineering, Vol. 27(4), pp. 559-569.

Ouellet, J. and Servant, S. (2000) In situ mechanical characterization of paste backfill with a self-boring pressuremeter, CIM Bulletin, Vol. 93(1042), pp. 110-115.

Rankine, R. and Sivakugan, N. (2007) Geotechnical properties of cemented paste backfill from Cannington Mine, Australia, Geotechnical and Geological Engineering, Vol. 25(4), pp. 383-393.

Revell, M.B. (2004) Paste - how strong is it?, In Proceedings 8th Int. Symp. on Mining with Backfill, The Nonferrous Metals Society of China, Beijing, China, pp. 286-294.

Rotta, G.V., Consoli, N.C., Prietto, P.D.M., Coop, M.R. and Graham, J. (2003) Isotropic yielding in an artificially cemented soil cured under stress, Géotechnique, Vol. 53(5), pp. 493-501.

Simms, P. and Grabinsky, M. (2009). Direct measurement of matric suction in triaxial tests on early-age cemented paste backfill. Can. Geotech. J. 46(1), pp. 93-101.

Skempton, A.W. (1960) Effective stress in soils, concrete and rocks, Pore Pressure and Suction in Soils, Butterworths, London, pp. 4-16. 
Thakur, N. (2008) Characterization of Strength Properties of Columns-Consolidated Cemented Paste Backfill at LaRonde Mine, Training Course Report, UQAT, 19 p.

Yilmaz, E., Belem, T., Bussière, B. and Benzaazoua, M. (2008) Consolidation characteristics of early age cemented paste backfill, In Proceedings 61st Canadian Geotechnical Conference, Edmonton, Alberta, pp. 797-804.

Yilmaz, E., Benzaazoua, M., Belem, T. and Bussière, B. (2009) Effect of curing under pressure on compressive strength development of cemented paste backfill, Minerals Engineering, Vol. 22(9-10), pp. 772-785. 